\title{
A INFLUÊNCIA DO PLANO DE DESENVOLVIMENTO DA ESCOLA NO PLANEJAMENTO DA ESCOLA PÚBLICA EM PERNAMBUCO
}

\author{
Luiz Alberto Ribeiro Rodrigues ${ }^{1}$, Anderson de Alencar Menezes ${ }^{2}$ \\ ${ }^{1}$ Doutor em Educação pela Universidade Federal de Pernambuco - UFPE, Docente adjunto da Universidade de \\ Pernambuco. E-mail: luiz.rodrigues@upe.br \\ ${ }^{2}$ Doutor em Ciências da Educação pela Universidade do Porto/Portugal. Docente Associado I da Universidade Federal \\ de Alagoas - UFAL. anderufal@gmail.com
}

\section{RESUMO}

Este artigo visa compreender as implicações do Plano de Desenvolvimento da Escola (PDE) no planejamento da escola pública. O PDE é tomado como representativo da política gerencialista em desenvolvimento no Brasil, particularmente na rede estadual em Pernambuco, lócus desta investigação. Utilizando-se da abordagem cognitiva de política pública (MULLER; SUREL, 2002), tendo sido os dados foram analisados a partir de uma visão dialética de gestão, em que o sujeito exerce um papel preponderante no nível da coordenação da ação. Observou-se que o desenvolvimento dessa política aumentou a regulação das escolas por meio de seu planejamento e fortaleceu o controle dos resultados da aprendizagem. O processo de participação instituído pelo PDE acabou por diminuir a função dos colegiados, ao mesmo tempo em que não favoreceu a percepção da escola em sua complexidade. Após quase duas décadas do desenvolvimento deste plano, aliado a política de recompensa por resultados instituída em Pernambuco, pode-se concluir que o PDE vem contribuindo para elevar a postura de passividade observada no discurso dos docentes, frente aos princípios do gerencialíssimo na gestão da escola enfatizados por este Plano. A gestão democrática ainda está distante de ser alcançada, na medida em que os princípios de autonomia e de participação, fundamentais neste sistema de poder, assumem no PDE um significado técnico e operacional em detrimento ao sentido político-pedagógico esperado.

Palavras - chave: Política Educacional. Gestão Escolar. Escola pública.

\section{HE INFLUENCE OF THE SCHOOL DEVELOPMENT PLAN IN THE SCHOOL PLANNING IN PERNAMBUCO}

\begin{abstract}
This article aims to understand the implications of the School Development Plan (PDE) in public school planning. The PDE is taken as representative of the managerial policy in development in Brazil, particularly in the state network in Pernambuco, the locus of this investigation. Using the public policy cognitive approach (MULLER; SUREL, 2002), the data were analyzed from a dialectical view of management, in which the subject plays a preponderant role in the coordination of action. It was observed that the development of this policy increased the regulation of schools through their planning and strengthened control of learning outcomes. The participation process instituted by the PDE ended up reducing the function of the collegiate, while at the same time did not favor the perception of the school in its complexity. After almost two decades of the development of this plan, allied to the policy of reward for results established in Pernambuco, it can be concluded that the PDE has contributed to raise the passivity posture observed in the teachers' discourse, against the principles of managerialism in school management emphasized by this Plan. Democratic management is still far from being achieved, since the principles of autonomy and participation, fundamental in this power system, assume in the EDP a technical and operational significance to the detriment of the expected political-pedagogical sense.
\end{abstract}

Keywords: Educational Policy. School management. Public school. 


\section{INTRODUÇÃO}

A escola, em qualquer configuração ou contexto político e histórico será sempre, na sua essência, uma escola, uma instituição sociocultural e socioeducativa a quem a sociedade delega e espera, a função de preparar crianças, adolescentes e jovens para o exercício da cidadania. Como instituição, "a escola é o lugar de concepção, realização e avaliação de seu projeto educativo, uma vez que necessita organizar seu trabalho pedagógico com base em seus alunos" (VEIGA, 2002. p. 1). Sua organização se justifica em função dos seus objetivos, na medida em que existe para realizar ações específicas voltadas ao desenvolvimento da aprendizagem, e a formação de valores e atitudes voltadas à cidadania. Seus objetivos estão voltados para desenvolver amplo processo de educação e de formação de pessoas. Como qualquer organização social, a escola segue princípios e procedimentos clássicos de gestão, tais como as funções de planejamento, de coordenação e de avaliação do trabalho. Além disso, por sua natureza essencialmente humana, lhe é peculiar a organização de um processo de gestão de pessoas, voltados a mobilizar esforços dos vários grupos inerentes a si, entre os quais os servidores técnicos, os professores, os estudantes e as famílias dos estudantes, em torno do complexo e desafiador processo educativo.

No Brasil, a partir da década de 1990, no contexto da reforma do estado brasileiro, percebeu-se o fortalecimento da função de regulação estatal, atingindo em cheio a escola, tornando-a a partir de então, o centro das atenções das políticas educacionais. A regulação deu início a processos de ingerência na escola, por meio do planejamento, no sentido da responsabilização e do monitoramento, afetando diretamente a cultura de gestão da instituição escolar, na sua ainda frágil experiência democrática.

São marcos dessa política o Programa Dinheiro Direto na Escola (PDDE) e o Plano de Desenvolvimento da Escola (PDE escola), implementados no âmbito do poder central ao longo dos últimos vinte anos ${ }^{1}$. Espelhados na administração empresarial, a lógica do PDDE e do PDE articula ações com vistas a mudança na cultura da gestão da escola, a partir do planejamento estratégico e de seus desdobramentos, resultando em ações que

\footnotetext{
${ }^{1}$ PDDE e PDE serão referidos a partir de então como política do PDE.
}

provocaram modificações diretas no âmbito da rotina escolar, tais como o trabalho pedagógico, a gestão do trabalho docente, a perspectiva da qualidade da educação, pondo em cheque, dessa forma, a ambiência educativa a ser desenvolvida pela instituição escolar. A lógica dessa política foca o controle nos resultados, o que impacta diretamente na concepção da gestão das escolas públicas, na medida em estabelece conexões pouco claras relativas aos limites entre a gestão da esfera pública e aos interesses da esfera privada. De certa forma, acreditamos que o PDDE e o PDE materializam em certo sentido, mudanças ocorridas no papel do Estado.

Em Pernambuco, no contexto dessa política de resultado, a rede estadual de educação vem se destacando pelo avanço significativo nos indicadores nacionais de avaliação da educação, tendo como referência o Índice de Desenvolvimento da Educação Básica, (IDEB)2. Até 2005, a posição de Pernambuco no IDEB figurava entre as mais baixas posições, se comparado aos demais estados do Brasil. Nesse ano, nas séries iniciais, as escolas foram avaliadas com índice de $(3,2)$; nas séries finais $(2,7)$ e no ensino médio $(3,0)$. Nessa avaliação a média nacional foi de $(3,8)$ para as séries iniciais, $(3,5)$ para as séries finais e $(3,4)$ para o ensino médio. Em 2007, a média nacional foi elevada, passando as séries iniciais para $(4,2)$; as séries finais para $(3,8)$ e o ensino médio para $(3,5)$. Também em 2007, Pernambuco não acompanhou a média nacional, embora tenha elevado o índice, chegando, nas séries iniciais a $(3,6)$; nas séries finais $(2,8)$ e no ensino médio a $(3,0)$.

Em 2015, passados uma década, o Estado contabilizou avanços sistemáticos nos índices de qualidade na educação, chegando a figurar entre os estados com os mais elevados índices educacionais, liderando o ranking junto com o Estado de São Paulo, ambos com nota 3,9. Grande parte dessa mudança deveu-se a decisões políticas implementadas pelo governo liderado por Eduardo Campos, em seus dois mandatos (2007 - 2010 e 2011 a 2014), no sentido investir e monitorar os resultados das escolas, em função da avaliação externa. A partir de então vivenciouse no âmbito da Secretaria de Educação, estratégias de gestão da política educacional, que

\footnotetext{
${ }^{2}$ O IDEB foi criado em 2007 pelo Instituto Nacional de Estudos e Pesquisas Educacionais Anísio Teixeira (Inep), e é divulgado a cada dois anos. O desempenho é comparado com as metas calculadas a partir da primeira edição, em 2005, e projetadas para todas as edições futuras, até o ano de 2021
} 
incluiu, entre outros, a ampliação do número de escolas de tempo integral, investimentos em infraestrutura, atualização dos currículos e mudanças no formato de remuneração dos profissionais da educação.

A política gerencial que chegou as escolas atingiu suas áreas vitais, tais como o currículo, o monitoramento do ensino dos conteúdos do currículo, o controle sobre a função de seus gestores, a mensuração de seus resultados de aprendizagem, o planejamento e financiamento de ações estratégicas, a formação dos gestores entre outros.

Entende-se nesse contexto, ser necessário ter uma visão dialética do processo político educacional presente na gestão da escola e considerá-lo a partir de uma dupla relação interdependente entre sujeito e instituição, ou seja, considere-se de um lado, o ponto de vista do interesse da organização institucional e de outro, o ponto de vista dos interesses das pessoas. Pode-se considerar então que nas atuais políticas de gestão em desenvolvimento da escola co-existem um tipo de administração ou de gestão do instituído e outro da administração ou de gestão do instituinte. $O$ instituído são os meios materiais, as formas institucionalizadas. 0 instituinte são as pessoas envolvidas na vida da instituição (BOUFLEUER, 2001).

Parte-se do pressuposto de que no desenvolvimento de políticas há que se considerar a existência de uma relação dialética de mediação do que foi instituído com o sujeito. Desse modo, pode-se pensar em uma relação entre o instituído e o instituinte, na medida em que os processos comunicativos se estruturam a partir de uma teoria da ação que repousa na noção de agir comunicativo, para em seguida incorporar a perspectiva do sistema. Ou seja, no âmbito das pessoas, do sujeito (instituinte), o mesmo exerce um papel preponderante no nível da coordenação da ação. O instituído é nesse sentido, formas já institucionalizadas, um processo posterior a uma decisão do sujeito, significa assim, que o instituído estará sempre na dependência do instituinte. Nesse sentido, pensar as influências da política do PDE na gestão escola, prescinde considerar que ela ocorre sempre na dependência do instituinte, em tal sentido, assume-se no âmbito da cultura escolar, uma mediação que é mobilizada, primeiramente, pelos sujeitos que fazem a política da instituição de ensino.
O objetivo deste artigo é compreender as implicações do Plano de Desenvolvimento da Escola (PDE), no planejamento da escola pública, a partir da experiência da rede estadual em Pernambuco, no período de 1998 a 2017. Nesse sentido apresenta um quadro teórico para pensar - agir comunicativo aplicado às instâncias do institucional-administrativo, a necessidade de passar de uma visão positivista e gestionária da Instituição Escolar para uma visão mais dialética e performativa dos procedimentos, próprio da dinâmica das políticas. Caracteriza as mudanças ocorridas no PDE escola no período de 1998 a 2017 e analisa seus efeitos na cultura de planejamento escolar em relação aos princípios democráticos. Este estudo vem em continuidade a uma pesquisa no âmbito do doutorado (RODRIGUES, 2013), que analisou a primeira década do PDE em Pernambuco.

Esta pesquisa utilizou-se do caminho teórico metodológico defendida por Muller e Surel (2002), conhecida como abordagem cognitiva de política pública, combinado com a teoria de discurso e de análise de discurso em Norman Fairclough (2001). Parte-se da hipótese de que a ação pública no estado moderno é resultante de um dinâmico processo de práticas sociais, em um determinado momento histórico, capaz de processar a construção social da realidade, conforme Muller e Surel (2002). A abordagem cognitiva proposta por este autor indica que os modos de ação do Estado moderno estão amparados em uma lógica de posicionamento, isto é, toda ação pública acontece dentro de modelos conceituais, chamados de paradigma, sistema de crença, ou mesmo referencial. Assim, todo processo político, atribui necessariamente uma importância fundamental aos valores, às ideias $e$ as representações.

0 processo de análise constituiu, sobretudo, um processo de identificação, descrição e de interpretação dos discursos, a partir da relação entre os textos e a prática social. Os procedimentos aqui postos não foram tomados como um esquema fixo e sim utilizados oportunamente. Buscou-se assim identificar conceitos chaves que estão em questão, provocando e alimentando o processo de mudança discursiva. Entendendo-se que a mudança surge com as soluções apresentadas à problematização de conceitos, soluções essas, de caráter inovador, criativo, e por si representam ações de transgressão à ordem discursiva. Tem-se 
como princípio, de que é a prática que legitima o discurso e, ao mesmo tempo, o discurso é uma parte da prática.

Os dados desta pesquisa foram levantados através de documentos oficiais, estudos anteriores e complementados por entrevistas semiestruturadas, entre os meses de maio a agosto de 2017, realizadas em sete escolas da educação básica da rede estadual de Pernambuco, localizadas na Zona da Mata Norte (03), na Região Metropolitana do Recife (03) e no Agreste Meridional (01). Todas as escolas estão integradas a política do PDE por um período mínimo de 07 anos. Como amostra, foram entrevistados 06 diretores, 04 técnicos educacionais, 05 professores do ensino médio e 03 professores do ensino fundamental. Participaram na condição de entrevistadores 03 estudantes do mestrado profissional em educação da Universidade de Pernambuco (UPE). As entrevistas no formato semiestruturadas, apresentadas como questionário básico se constituíram como instrumento de coleta de dados e sentidos. Visou favorecer a descrição e a explicação do fenômeno político vivido e percebido pelos atores da escola.

\section{PENSANDO INSTITUIÇÕES APRENDENTES: DA LÓGICA DA EFICÁCIA À LÓGICA DA COOPERAÇÃO}

A instituição escolar, a partir de uma lógica da gestão do conhecimento, se delineia sobre a passagem de um paradigma instrucionista, cartesiano e mecânico, para um paradigma norteado pela noção de aprendizagem. O maior desafio de qualquer organização é romper com o modelo taylorista que vigorou durante anos e que ainda se faz notar na organização de algumas empresas modernas, particularmente em muitas instituições escolares. Este modelo cria a uniformização dos sujeitos, dos procedimentos e das estruturas. A partir do paradigma da aprendizagem, o sentido deve ser o de revalorizar os sujeitos cultivando posturas cada vez mais complexas num contexto multifacetado.

Esta nova cultura da aprendizagem emerge nos contextos de sociedades interculturais e multiculturais em que surgem novas subjetividades em situações pluriétnicas a partir das diversidades de gêneros e culturas. Assim, nesta nova cultura da aprendizagem as competências cognitivas têm que ser aprendidas de forma simultânea ao desenvolvimento da sensibilidade ética e metacognitiva.

É preciso pensar a partir de uma Antropologia do Projeto, a partir de um paradigma da aprendizagem e da complexidade, menos cartesiano e compartimentado, e, neste âmbito, não menos lógico em suas estruturas e formas. Pois, pensar a partir da lógica da aprendizagem e não do puro instrucionismo, nos permite pensar em organizações complexas.

É como nos diz Matos (1999):

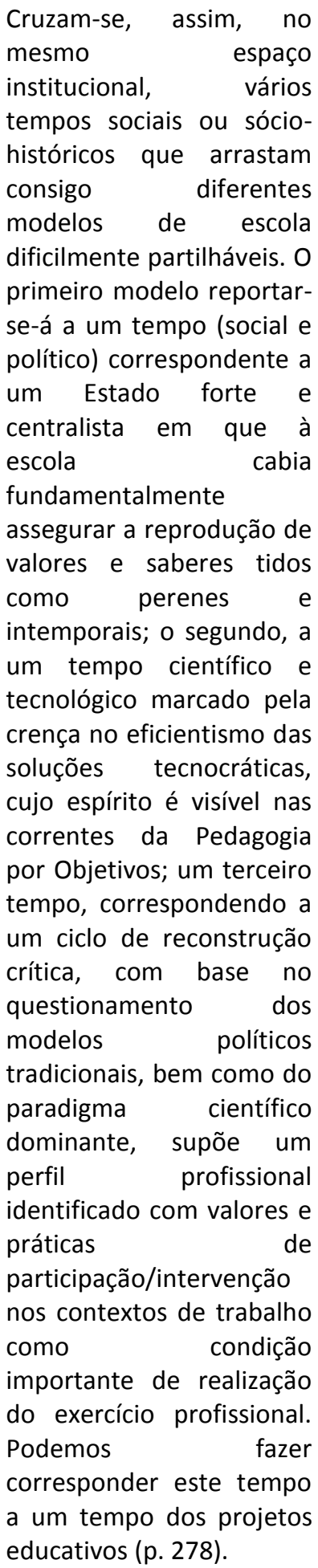


Deve-se sublinhar a importância do agir comunicativo aplicado às instâncias do institucional-administrativo. É ímpar a distinção feita por Boufleuer (2001), quando entende esta relação a partir de duas ordens, uma instituída (normas, regimentos da instituição) e o instituinte (os atores, os agentes) da mesma. Esta relação tem uma ligação íntima com a maneira de Habermas perceber a questão a partir da relação entre sistema e mundo-da-vida.

Pens pensar o InstitucionalAdministrativo à luz da teoria do agir comunicativo significa passar de uma visão positivista e gestionária da Instituição Escolar para uma visão mais dialética e performativa dos procedimentos. Ou seja, visa estabelecer a relação entre instituinte e instituído a partir do espaço público que é uma das características peculiares de toda Instituição Educativa.

Falar de uma nova cultura organizacional implica pensar um novo paradigma. De um paradigma tecnicista e instrumental, para uma ação comunicativa. Isto significa passar de uma cultura organizacional dos instrumentos para o sujeito da cultura organizacional.

Ao longo da história, a organização do trabalho humano variou de acordo com os tempos e as mentalidades. Entre os gregos, a organização da cultura humana se dava mediante a concepção da cidade-estado grega, a Polis. Nela, filósofos como Platão e Aristóteles percebiam o potencial da virtude na arte de bem governar a cidade. A Areté (virtude) era o resultado de uma prática no conjunto da Polis. Platão, no livro IV da República, pensa a CidadeEstado a partir da tricotomia da alma; esta, entendida aqui, como psyché ou mente. Já, para Aristóteles, sua importância é percebida na Ética a Nicômaco no livro $\mathrm{VI}$, quando nos remete à formação do habitus, enquanto locus originário da formação da vontade. Surge, portanto, a frónesis ou a prudência, enquanto sabedoria prática, ou capacidade e arte de bem julgar. Portanto, para os gregos, a questão da organização externa da cidade liga-se de modo imediato à questão da formação do cidadão grego mediante a prática da virtude. Virtuoso é o cidadão que busca a harmonia da Polis mediante o exercício individual e coletivo de práticas que conduzem ao aperfeiçoamento de si e da cidade.

Com o advento da modernidade, com o nascimento do sujeito moderno, os burgos, na constituição do cenário da burguesia nascente, nos levam a pensar no sistema de trocas. As cidades passam a ser o palco das novas organizações. Passa-se de uma cultura agrícola (feudal) para uma cultura sistêmica e racional e quantitativa (Idade Moderna).

Já a sociedade contemporânea se repensa a partir de outros paradigmas. Para além do paradigma técnico-científico, a sociedade do século XXI é conhecida como a sociedade do conhecimento, dos saberes múltiplos, transdisciplinares, complexos. Portanto, é a partir deste novo horizonte cultural complexo que devemos repensar a organização da Instituição escolar.

Urge pensar a Instituição Escolar a partir de uma Teoria da Ação da Comunicativa no âmbito contemporâneo. Sobretudo pensá-la no modelo habermasiano significará uma nova compreensão dos modelos e dos atores envolvidos no âmbito da Instituição Escolar.

O modelo que estamos propondo nasce no contexto da emergência de subjetividades atravessadas pela historicidade e pelas narrativas que fazem o seu cotidiano num horizonte cultural denso e ao mesmo tempo complexo.

Criticar este modelo gerencialista de condução da Instituição escolar torna-se um imperativo no contexto hodierno. Sobretudo pelo fato do PDE ter influenciado ao longo destes anos uma política pública de gerenciamento das escolas de Pernambuco que se regeu unicamente por visões mecanicistas e fragmentadas em face à problemática da gestão da Instituição Escolar e suas multifacetas transformações no cenário contemporâneo.

Recuperando a historicidade da Instituição Escolar é possível pensar com Dubet (2004) é que a pergunta por uma Escola Justa passa necessariamente por uma relação intrínseca entre justiça cognitiva e justiça social. O PDE em sua estruturação fica indiferente diante desta relação, sendo incapaz de compreender e interpretar as profundas mutações que perpassam internamente as dinâmicas da Instituição Escolar.

De fato, como bem demonstra Botler (2004) devemos pensar a Escola como organização Comunicativa a partir de uma teoria da ação comunicativa a partir do paradigma habermasiano. Ou seja, os modelos comunicativos de ação comportam todas as funções da linguagem, em que a fala comporta uma ação linguística que preenche uma tipologia social de ação, cujo objetivo final é não reduzir a 
fala a um puro semanticismo nem tampouco a ação a um mero agir estratégico e instrumental.

A fundamentação do agir racional motivado por regras no âmbito da Instituição Escolar compreende uma clara fundamentação democrática. Isto significa que a ação comunicativa na construção das normas e regras coletivas passa por uma interpretação do conceito de cidadania ativa num contexto de clara opção democrática.

Implica dizer que as narrativas construídas neste âmbito de clara opção democrática na Instituição Escolar não permite nenhuma forma de dominação ou manipulação a partir do conceito de uma tipologia social, entendida aqui, como ação comunicativa.

Neste sentido, ainda na esteira de Botler (2004) quando trata da relação entre ação comunicativa e gestão coletiva há um espaço de construção da reflexividade promovida pela ação coletiva na construção das intersubjetividades no âmago da gestão coletiva.

Neste âmago de compreensão, devemos retomar Hermann (1996) em que a construção de uma racionalidade na escola e na gestão escolar deve se reduzir às escolhas meramente técnicas e estratégicas. Mas deve-se pensar que a construção da Instituição Escolar é compreendida por uma racionalidade ético-formativa permeada de valores que dizem respeito à construção do respeito, da tolerância e da integridade física e psicológica dos atores envolvidos.

Como nos diz Hermann (1996, p. 88)

$$
\begin{aligned}
& \text { O fundamento da ação } \\
& \text { dialógica encontra-se na } \\
& \text { participação do sujeito em } \\
& \text { um mundo compartilhado } \\
& \text { com outros sujeitos. Isso } \\
& \text { tem validade para as } \\
& \text { diferentes instâncias do } \\
& \text { processo pedagógico, seja } \\
& \text { no plano da relação } \\
& \text { professor-aluno, seja no } \\
& \text { plano da definição da } \\
& \text { política educacional, da } \\
& \text { administração e da relação } \\
& \text { com outras áreas do } \\
& \text { conhecimento científico. A } \\
& \text { educação escolar precisa } \\
& \text { fazer valer as formas de vida } \\
& \text { que possam dar sentido à } \\
& \text { formação do sujeito } \\
& \text { racional, ou seja, garantir os } \\
& \text { processos de reprodução } \\
& \text { cultural e de formação da } \\
& \text { identidade. }
\end{aligned}
$$

Em síntese, no dizer de Hermann (1996), uma razão comunicativa em ação pedirá das Instituições escolares uma mudança profunda de paradigma. Considerando que a Escola é parte constitutiva do mundo da vida, no sentido habermasiano, em que as produções simbólicoculturais são fomentadas e fecundadas neste âmbito. Assim, cabem as Instituições Educativas regidas pela razão comunicativa, maximizar os aspectos a seguir, literalmente Hermann (1996) p.89):

promover a capacidade discursiva daqueles que aprendem; • promover condições favoráveis a uma aprendizagem crítica do próprio conhecimento científico; - inocular a semente do debate, considerando os níveis de competência epistêmica dos alunos; - promover a discussão pública sobre os critérios de racionalidade subjacentes às ações escolares, seja através dos conhecimentos prevalentes no currículo, seja pela definição de políticas públicas que orientem a ação pedagógica; • estimular processos de abstração reflexionante, que permitam trazer a níveis superiores a crítica da sociedade e dos paradoxos de racionalização social e, a partir daí, realizar processos de aprendizagem, não só no plano cognitivo, como também no plano político e social; - promover a continuidade de conhecimentos e saberes da tradição cultural que garantam os esquemas interpretativos do sujeito e a identidade cultural.

\section{POLÍTICA COMO OBJETO DE ESTUDO}

No âmbito das ciências sociais, as políticas públicas se apresentam como um campo de estudo complexo, dado o modo como são elaboradas e postas em desenvolvimento, se materializando em um ou mais programas de um determinado governo, voltados a um ou mais setores da sociedade Elas são, desse modo, 
constituídas de relações complexas, mediadas por elementos que se ligam entre si, a partir de uma concepção conceitual de relações e de saberes (MULLER; SUREL, 2002).

O termo política, no seu original sentido grego, relaciona-se ao sentido do exercício do poder na cidade, de cuidar do que é público, das habilidades no trato das relações humanas. $\mathrm{Na}$ contemporaneidade este termo adquiriu novas facetas, sobretudo com a emergência da esfera do social em que se pretende a repolitização das três esferas de valor, a ciência, a moral e a arte, pensando em uma esfera política pública. Este termo compõe como um conjunto articulado de elementos em desenvolvimento ou mesmo "quadro geral de ações" que combina leis, atribuições, pessoal voltado para realizar objetivos (MULLER; SUREL, 2002), podendo ser percebido como uma organização, mesmo que em certo sentido, informal, ideológica.

A existência de políticas públicas está condicionada a vivência de relações entre diversos organismos da sociedade, entre os quais o governo, instituições multilaterais, grupos econômicos, grupos ideológicos, entre outros, compondo assim uma rede complexa de interesses e de relações de poder. De modo especial, no campo do estrato político capitaneado pelo PDE, há um contexto histórico sobre o qual não se pode descuidar, sobretudo quanto ao embate em torno de redes de interesses, devendo-se considerar o "[....]histórico embate sobre o fundo público, num cenário de interpenetração entre esfera pública e privada, em detrimento do público" (DOURADO, 2017, p. 176).

Nesse contexto, um ingrediente central na constituição dessa política é processo de disputa, especialmente quanto ao financiamento, que revelam articulações políticas de setores privados, pondo riscos a política por formatos de privatização, alterando a concepção de que financiamento público é exclusivo para o setor público, contrariando os princípios de cooperação e colaboração, marcos da relação que propõe o PNE entre os entes federados (DOURADO, 2017).

Revela-se assim interesses dessas políticas em intervir na gestão da educação

[...] expressa uma
tessitura sócio-política
complexa, que articula
com às agendas
transnacionais, ao Estado

nacional, à relação entre os entres federados, às especificidades do sistema educacional brasileiro, à gestão, à avaliação e ao financiamento, â qualidade e às concepções políticas-pedagógicas norteadoras, entre outros" (DOURADO, 2017, p. 176).

Nesse contexto, por vezes pode-se considerar que, em um certo sentido, política pode ser uma 'organização' em que se presume na sua constituição algo de 'coerente', mas não é isso que ocorre de fato, ao contrário, pode ser permeada de várias manifestações de 'incoerências' no seu processo. Esta, é, sem dúvida, uma questão desafiadora para o investigador de política pública, no sentido de que, no decorrer do processo de análise, ele necessita construir um sentido, uma relação lógica para as diversas ações ocorridas no decorrer do processo de elaboração e implementação. Por outro lado como advertem Miller e Surel (2002), é necessário para este tipo de estudo, a elaboração de um quadro de análise que possibilite ir além da simples abordagem.

No movimento da política pública instituída, um pressuposto a considerar na investigação é que, sobre ela não ocorre uma implementação direta, uma reprodução automática do marco legal, mas segue-se um processo de desenvolvimento. Desse modo podese pensar que, o que é publicado como política pública, como texto legal, neste caso para a educação, sofre alterações, interpretações e reinterpretações ao longo do seu desenvolvimento por parte de seus 'desenvolvedores', autoridades públicas, gestores da educação, professores, profissionais técnicos da educação, estudantes e comunidade. Todos esses sujeitos exercem, no seu local de atuação, um papel ativo no seu desenvolvimento da política. $O$ que eles pensam, o que acreditam, o que defendem, dão a fisionomia da política, dão a ela novos significados advindos dos novos códigos sociais. É nesse sentido que deve-se considerar que as políticas educacionais prescindem, no chão da escola, do consentimento ou de algum grau de concordância em relação às suas finalidades e procedimentos, dos sujeitos individuais em relação a proposta institucional. 


\section{A PRIMEIRA DÉCADA DO PDE NO BRASIL E EM PERNAMBUCO}

A origem da política do PDE no Brasil
está relacionada, incialmente, aos encaminhamentos originários do Projeto Nordeste (PN), desenvolvido no período de 1984 a 1998. Esse programa, marco na política para o desenvolvimento do Nordeste brasileiro, inseriu a educação no rol dos condicionantes para o 'progresso'. No final da década de 1980, o governo brasileiro, influenciado pelo Banco Mundial (BM), aceitou o financiamento de um único programa para o desenvolvimento do Nordeste, na área da educação. O BM apresentou um diagnóstico sobre a realidade da educação no Nordeste, em que foram identificadas características e falhas dos sistemas educativos dos estados nordestinos 3 , com destaque para o problema da má qualidade da gestão das escolas, oriunda da cultura política, traduzida como falta de capacidade de planejamento e de execução de políticas com independência, sem a ingerência de poder político momentâneo, com visão política para além de um mandato (TOMMASI, 2007). Some-se a este quadro a dependência dos estados do Nordeste a recursos oriundos do governo federal e ainda a falta de integração entre esses estados (TOMMASI, 2007).

O Projeto Nordeste foi nesse sentido um propulsor de uma política para "aumentar a aprendizagem estudantil, reduzir a repetência e a evasão e aumentar os índices de conclusão nos Estados participantes, através de melhoria da qualidade do ensino básico estadual e municipal e da eficiência do gerenciamento educacional" (TOMMASI, 2007, p. 217). As ações propostas foram ordenadas para serem realizadas nos âmbitos estadual e nacional. No âmbito dos estados dessas regiões, foram propostas medidas voltadas a melhorar a capacidade de gerenciamento educacional das secretarias de educação; melhorar a qualidade do Ensino Básico nas escolas estaduais e municipais através do fornecimento de livros, materiais didáticos e assistência técnica; aperfeiçoamento do pessoal de ensino básico através do fornecimento de assistência técnica; Execução de subprojetos estaduais e municipais (rede física, equipamentos, e mobiliário escolar); e estabelecimento de fundo, no MEC, para

\footnotetext{
${ }^{3}$ Ver: UNICEF Y la educación básica. Nova Yorque. UNICEF - Sección Educación. 1995.
}

fornecer financiamento a fundo perdido ((TOMMASI, 2007).

Vem daí um grande impulso ao processo de descentralização administrativa e o incentivo aos estados em relação ao uso de recursos federais, elevando a dependência, a centralização e o controle da política do MEC, materializado no Programa de Manutenção e Desenvolvimento do Ensino Fundamental (PMDE).

O PDDE, sobretudo no seu aspecto de financiamento, foi instituído em substituição ao PMDE. Implantado pelo MEC e é executado diretamente pelo Fundo Nacional de Desenvolvimento Escolar - FNDE. Este programa institui o planejamento estratégico como um instrumento para o fortalecimento da autonomia escolar e para a sistematização dos procedimentos, atividades e ações implementadas em seu ambiente. A estrutura da gestão do PDDE é fundamentada no voluntarismo, inicialmente através da Unidade Executora (UEx), instância que camufla a dimensão centralizada e desconcentrada da gestão financeira da escola, separando o nível da concepção, realizada pelo nível central, da execução (ao nível periférico). As mudanças na gestão financeira da escola a partir da UEx são marcadas por uma "re-centralização do poder do estado nas decisões políticas e nas estratégias e pela desconcentração das decisões operacionais referentes à gestão do programa, e não pela reorganização democrática do poder e da autoridade na gestão dos recursos públicos das unidades de ensino" (SILVA, 2005, p. 213).

Dois anos após a criação do PDDE, em 1997, concebe-se o PDE, através do Fundo Nacional de Desenvolvimento da Educação Fundescola, impulsionado por recursos financiados através do Banco Mundial. Este programa representa a continuidade da política iniciada no Projeto Nordeste e PDDE, no sentido de incrementar ações de reforma de gestão da educação, de modo particular nas regiões Norte, Nordeste e Centro-Oeste do Brasil. A estratégia inicial do Fundescola foi fomentar o planejamento da escola, diminuir gastos públicos com a educação e impulsionar a massificação do Ensino Fundamental nessas regiões, detentoras do maior índice nacional de evasão e reprovação escolar.

O Fundescola financiou diversas ações integradas, mas a sua principal ação foi o PDE, considerado o programa de maior visibilidade e 'carro-chefe' dessa política. Ele vai difundir na 
escola a cultura gerencial, com ênfase no planejamento estratégico centrado em resultados, com foco em uma suposta aprendizagem do aluno.

A ação deste Plano nas escolas obteve rápido avanço com um cronograma, que transcendeu o período restritos a cada governo. Iniciado no período do governo de Fernando Henrique Cardoso, no ano de 1998, o PDE manteve-se no decorrer do primeiro governo Lula, de 2002 a 2006, persistindo e se institucionalizando para todos os estados da federação a partir de 2007 e mantendo-se até então nos governos seguintes.

O discurso do PDE, ao longo de sua implementação no Brasil, segue princípios e concepções que balizaram o processo de reforma administrativa do Estado, tais como a descentralização administrativa, a concentração do controle por parte do Estado, a responsabilização da sociedade civil na efetivação dos direitos sociais e uma relação nebulosa entre a dimensão público-privado.

0 modelo de gestão, sugerido às escolas dos estados mais pobres do Brasil, foi desse modo aprofundado pelo PDE, por meio da inserção da escola na cultura de performatividade competitiva, pensada pelo estado liberal, de modo a combinar o princípio da descentralização com incentivos para se produzir a partir de uma lógica de mercado, que é a lógica da eficácia. Essa política indicou um novo perfil para as escolas, tornando funções de ensino e de aprendizagem um processo de produção sob o controle da sociedade, avaliado pelo Estado.

O princípio da descentralização que permeia $O$ PDE procura transferir a responsabilização, sem oferecer as condições necessárias para o exercício do poder efetivo da sociedade na garantia dos direitos fundamentais. Impõe-se assim uma nova relação entre estado e sociedade civil, em que atribuições, antes pertencentes ao poder central, como a educação, que pressupõe autonomia legal, funcional e financeira para os seus efetivadores, são delegadas à sociedade civil sem as condições necessárias para sua execução (PERNAMBUCO, 2000c).

No Estado de Pernambuco o PDE escola construiu uma trajetória com características próprias, marcada no geral por um processo de resistência às diretrizes do governo central presente nesta política. A partir de 1999, foi instituída uma nova política educacional, liderada pelo governador Jarbas Vasconcelos (PMDB), que abriu os espaços para a UEx e para o financiamento do PDE e do PDDE direto às escolas. Em 2000, 75\% das escolas públicas da rede estadual tinham aderido ao PDE e instalado sua própria UEx. Também, naquele ano, o Sindicato dos Trabalhadores em Educação de Pernambuco (SINTEPE) denuncia os efeitos da Unidade Executora (UEx) como uma ingerência do setor privado no setor público, uma questão ideológica.

Em 2002, retoma-se o discurso contrário ao modelo de identidade de escola proposto pelo PDE e assim, em 2003, não aconteceu expansão do PDE nas escolas da rede estadual. Não havia adesão da Secretaria de Educação e o BM estava propondo um empréstimo ao Estado, para que pudesse editar seu próprio PDE. Assim, a partir de 2005, Pernambuco assume um formato próprio para este Plano, com recursos de empréstimo com o próprio BM. É lançado, paralelamente ao $\mathrm{PDE}$, o programa Educação de Qualidade (EDUQ) com orientações (Manual) próprio com uma diferente concepção de Escola e de planejamento. O EDUQ trouxe uma concepção de escola voltada à organização de práticas pedagógicas, redefine a função política do planejamento, retomando assim o discurso sobre a gestão colegiada na perspectiva democrática (RODRIGUES, 2013).

Pode-se afirmar que o PDDE e o PDE escola são na verdade estratégias da mesma política, e dão suporte à proposta de descentralização gerencial. Na conclusão, este estudo ${ }^{4}$ destacou aspectos da vida escolar afetados diretamente por essa política, primeiro ocupando a atenção da escola com o planejamento estratégico, em seguida, desqualificando experiências, ainda que frágeis, de formatação do PPP na escola.

Outro aspecto destacado, é a tentativa de reduzir a concepção de qualidade unicamente à resolução de problemas administrativos, desconsiderando, assim, as condições físicas e humanas necessárias ao pleno desenvolvimento de atividades pedagógicas na escola. A escola, no entanto, sabe que a qualidade exige a garantia de condições básicas, a começar pela disponibilidade de pessoal qualificado, professores com tempo para instituição, técnicos para o atendimento burocrático e para zelar pelos espaços físicos,

${ }^{4}$ Pesquisa realizada no âmbito do doutorado em 2009 e publicada em 2013 (RODRIGUES, 2013). 
cuidar da convivência e do acompanhamento de seus estudantes.

\section{CONFIGURAÇÕES OPERACIONAIS DO PDE NA ESCOLA A PARTIR DE 2011}

Mantendo-se a mesma lógica de gestão por meio de planejamento estratégico na escola, a partir de 2011, o formato da política do PDE escola sofreu alterações na sua forma de operacionalização, sobretudo quando o controle sobre o planejamento da escola, que foi acelerado com o uso dos dados do Senso Escolar e do IDEB, articulados por um sistema online, chamado de PDDE interativo, elaborado pelo MEC em conjunto com as secretarias estaduais e municipais de educação. Inicialmente esse sistema foi utilizado por escolas com baixos índices no IDEB, alvo prioritário do PDE escola e a partir de 2012, disponibilizado para todas as escolas públicas, para fins de "apoio à gestão escolar", como condição para financiamento ou não (BRASIL, 2015).

A partir de 2015, essa política passa a ser operacionalizada por meio da plataforma PDDE Interativo, como um sistema único, universalizado, para o planejamento de todas escolas que estavam cadastradas no Censo Escolar de 2014. Em termos operacionais, o PDDE interativo amplia o alcance do gerencialismo, consolidando $\mathrm{o}$ formato de planejamento estratégico da escola iniciado em 1995, e aumentando a eficiência, consolidando a articulando informações, que acaba por aprimorar o sistema de controle e de regulação sobre a escola. $\mathrm{Na}$ atualidade é possível considerar que, do ponto de vista formal, o PDDE interativo tem mais informações sobre a escola do que ela mesma tem de si.

A partir do PPDE interativo, o PDE escola, passa a se constituir, do ponto de vista operacional, em uma etapa posterior, destinada a escolas com os piores índices. Assim, tenta se afirmar como um plano de apoio "à gestão escolar baseado no planejamento participativo e seu objetivo é auxiliar as escolas públicas a melhorar a sua gestão. Para as escolas priorizadas pelo programa, o MEC repassa recursos financeiros destinados a apoiar a execução de toda ou parte do seu planejamento" (BRASIL, 2015. p. 01). O que o MEC chama de escolas priorizadas, na verdade são aquelas com IDEB abaixo da média. $O$ planejamento, praticamente é formatado na etapa do PDDE interativo. No PDE escola há de fato um detalhamento dos itens a serem financiados.

O formato 'interativo' de planejamento e gestão assumido pelo PDDE, institui-se a partir dos dados integrados da escola, quando foram incluídos o Censo Escolar e os resultados do Índice de Desenvolvimento da Educação Básica $\left(I D E B^{5}\right)$, formulado para medir a "qualidade" do aprendizado nacional e estabelecer metas para a melhoria do ensino. O diagnóstico, etapa mais importante do planejamento, inclui dados em várias dimensões: indicadores e taxas; taxas de rendimento; ensino e aprendizagem; gestão; comunidade escolar e infraestrutura. Propôs o MEC que as informações do diagnóstico sejam construídas pelo Conselho Escolar ou por parte dele e disponibilizadas aos estados e municípios (BRASIL, 2015). A participação do Conselho Escolar na elaboração do diagnóstico não é algo factível, dado que na prática, só é possível no nível da constatação dos dados estatísticos, considerando que a plataforma já fornece as informações e sua leitura em gráficos e percentuais a partir do Censo Escolar e do IDEB, conduz os "planejadores" a realizarem uma leitura óbvia e induzida ao que está indicando os dados naquele momento. Assim, não há espaços para diferentes leituras ou interpretações subjetivas por parte do conselho escolar como sugerido pelo MEC. O sistema interativo só aceita diagnóstico "pré-definido" a partir dos dados formais indicados na tela, apenas a confirmação de que a escola encontra-se nesta ou naquela situação.

Embora tecnicamente este sistema apresente avanços na articulação das informações, sua real influência no planejamento das ações da escola é algo questionado, como sugere o estudo a seguir, realizado por Pinto (2015), que problematizou o PDDE Interativo, em sua aplicação no Distrito Federal (DF). O estudo foi gerado por uma demanda da comunidade escolar, que desejava o aprimoramento de sua gestão e do processo de ensino e aprendizagem e por isso utilizou-se a plataforma interativa. A pesquisa analisou a influência do comitê do PDDE interativo do DF na tomada de decisão das escolas, especialmente em relação aos seus respectivos planos de ação. Concluiu que os problemas associados à interação do comitê com as escolas são causados por ambas as partes, não

\footnotetext{
${ }^{5}$ O IDEB foi criado em 2007, pelo Instituto Nacional de Estudos e Pesquisas Educacionais Anísio Teixeira (Inep).
} 
se evidenciando uma influência relevante dos comitês sobre os planos gerais de gestão escolar nessas unidades. Mas afinal, que tipo de diagnóstico a escola é levada a fazer de si mesma? Quais fragilidades e ações lhes é permitido perceber e definir? O que a política do PDDE e PDE influenciou na gestão e no ambiente escolar?

\section{QUESTÕES SOBRE A GESTÃO ESCOLAR E SEUS PRINCÍPIOS}

No âmbito das instituições públicas de educação básica no Brasil, compete a gestão escolar a efetivação dos princípios da gestão democrática, conforme a LDB (BRASIL, 1996). Em seu artigo 14을 essa lei referenda o princípio da participação, como condição fundamental para o exercício da democracia a ser exercida pelos profissionais da educação e pela comunidade local, na elaboração do projeto político pedagógico através de conselhos escolares ou equivalentes.

A legitimidade democrática remete ao esforço coordenado e coletivo, a ideia de trabalho associativo realizado por pessoas autônomas, que analisam situações e tomam decisões sobre a escola, com base no consenso coletivo. Essa perspectiva deve evitar o decisionismo que não admite as conflitualidades e as interpelações que advém dos registros das coletividades, mas ao contrário, as considera na sua heterogeneidade (HABERMAS, 1997).

Esse paradigma de gestão guia-se por dois princípios centrais, quais sejam, a participação e a autonomia. O princípio da participação refere-se a capacidade política de mobilizar pessoas, envolver os diferentes sujeitos em torno de ideias, projetos coletivos, no sentido de tornar a escola o espaço da formação, de produção do conhecimento referenciado socialmente, da garantia de direitos e deveres. Participação é assim uma categoria política, um processo efetivo de exercício de poder, que traduz a capacidade individual ou coletiva de influenciar as decisões sobre o processo político pedagógico da instituição escolar.

É deste modo central para a gestão democrática, na medida em que acentua aspectos políticos, mais que aspectos técnicos, o que difere de outras concepções centralizadoras e burocráticas de administração. A participação como princípio busca atribuir a gestão, um sentido mais dinâmico, mobilizador, articulador e cooperativo em torno das decisões acerca do projeto social de escola.

A autonomia, por sua vez afirma o direito das unidades escolares públicas de educação básica integrarem progressivos graus de "autogestão", no sentido de participar ou seja, de engajamento em uma estrutura. Esse princípio se insere na dimensão administrativa e também sobre na organização político-pedagógica. Este princípio constitui-se assim em uma condição para a qualidade da escola, que deve ser acompanhada de outros condicionantes, tais como os de infraestrutura, pedagógica e material.

Uma expressão de sua autonomia é o desafio permanente da escola de pensar a si mesma e no seu futuro, um esforço coletivo de professores, técnicos, estudantes e comunidade local, em discutir e elaborar permanente processos de aprender e ensinar, frente a complexidade da função educativa que lhes compete, mediatizada por perspectivas éticas, políticas, pedagógicas e histórico-sociais.

Esses dois princípios constituem-se como essenciais para a qualidade da escola, na medida em que dizem respeito ao sentido e a condição da pessoa humana na estrutura educacional. Tornar a escola melhor, com condições de pensar e repensar a si mesma, implica necessariamente, [...] envolver o elemento humano, as pessoas e, através delas, mudar a cultura que se vive na escola, e que ela própria inculca" (ALARCÃO, 2001, p.19). No dizer desta autora, essa característica é da natureza da escola, podendo ser chamada de "escola reflexiva [...] uma organização escolar que continuadamente se pensa a si própria, na sua missão social e na sua organização, e se confronta com o desenrolar da sua atividade em um processo heurístico simultaneamente avaliativo e formativo" (ALARCÂO, 2001, p.25).

Não é uma tarefa simples pensar a mesma, exige-se uma sistemática investigação sobre si e sobre o ambiente político, social e econômico em que ela está inserida. Implica "na observação cuidadosa da realidade social, descobre os melhores caminhos para desempenhar a missão que the cabe na sociedade. Aberta a comunidade exterior, dialoga com ela. Atenta à comunidade interior, envolve todos na construção do clima, na definição e realização do seu projeto, na avaliação da sua qualidade educativa" (ALARCÃO, 2001, p. 26). O projeto da escola deve assim representar o que ela pensa de si mesma, "que conta com o 
empenho de cada um, porque foi interativamente construído através do diálogo entre seus membros, no entrelaçar de estratégias que vão do topo para a base e da base para o topo" (ALARCÃO, 2001, p. 26).

A mudança da escola é desse modo uma tarefa complexa, mas possível. Sugere esta autora que, assim como o ser humano, a escola tem a capacidade de aprender e desenvolver-se por interação. Nesse sentido afirma "se quisermos mudar a escola, devemos assumi-la com organismo vivo, dinâmico, capaz de atuar em situação, de interagir e desenvolver-se ecologicamente e de aprender a construir conhecimento sobre si própria nesse processo" (ALARCÃO, 2001, p.27).

$\mathrm{Na}$ perspectiva de gestão, o planejamento da escola carrega essa possibilidade de sistematizar o esforço dos sujeitos, em pensar e elaborar um projeto político de ação. As políticas atuais educacionais enxergam esse aspecto e centram atenção na dimensão técnica, mas de elevado impacto político, no planejamento da escola, nos moldes das organizações empresariais, com metas, monitoramento e responsabilização. É nessa perspectiva que se estabelece a política do PDE, fomentando essa lógica, desde 1995.

Não se pode negar que o planejamento tem muito de técnica para realizar um bom diagnóstico, pensar caminhos de solução a curto médio e longo prazo. No entanto, não se pode descuidar da dimensão ética, essa dimensão é fundamental à natureza social da escola, como destaca Alarcão, "tem-se falado muito sobre o pensamento estratégico das organizações, só que nesse pensamento tem-se muitas vezes esquecido, a dimensão ética, valorativa, humana, interpessoal" (ALARCÃO, 2001, p. 28). Uma escola é assim uma organização essencialmente aprendente, e por isso deve valorizar "a participação nas decisões, o direito à palavra, a capacidade de responsabilização e avaliação [...] assumidos como imprescindíveis" (ALARCÃO, 2001, p. 28).

Assim, uma expressão fundamental da gestão escolar é, antes de tudo, o seu planejamento conceitual, formulado a partir do Projeto Político Pedagógico (PPP). Este projeto não visa simplesmente a um rearranjo formal da escola, mas a busca pela qualidade em todo o processo vivido. Tem assim o PPP, um papel político de "mobilizar a comunidade escolar no sentido de organizar a prática pedagógica voltada aos interesses da maioria da população" (VEIGA, 2002 , p. 3). O pressuposto do PPP é a busca por "uma teoria pedagógica crítica viável, que parta da prática social e esteja compromissada em solucionar os problemas da educação e do ensino de nossa escola" (VEIGA, 2002, p.3).

Não se pode esconder que a escola atual sofre fortes influências do modelo neoliberal capitalista que constroem narrativas sociais e culturais que afundam a subjetividade em profundos individualismos, que geram competição e descaso total pelas questões públicas. Deve-se considerar que as pessoas que compõem o conjunto da escola não são naturalmente participativas e afeitas a práticas democráticas. O interior da escola reflete contradições do modelo neoliberal, carrega traços da conjuntura política ideológica capitalista vigente na sociedade brasileira. Nesse contexto não dá para pensar a escola, sem considerar que "a organização do trabalho pedagógico da escola tem a ver com a organização da sociedade" (VEIGA, 2002, p. 3).

O processo de regulação do qual a escola está sujeita através das políticas educacionais com foco na avaliação, no planejamento estratégico, no monitoramento e no controle de seu processo e sobretudo dos resultados, se contrapõe ao desafio de manter sua autonomia e a qualidade social, sendo esta uma luta permanente da escola.

\section{IMPACTOS NO PLANEJAMENTO DA ESCOLA}

$O$ termo planejamento nos remete a uma função de gestão ou mesmo ferramenta de administração que possibilita construir uma percepção acerca da realidade, avaliar os caminhos, construir um referencial de análise do futuro em função dos objetivos institucionais. Como ocorre em outras as organizações, o planejamento na escola vai além de um instrumento apenas técnico, na medida em que pode afirmar o exercício da prática democrática permanente, voltado à organização do trabalho pedagógico na perspectiva de sua razão de ser, a formação do cidadão. Nessa perspectiva o planejamento central da escola é o PPP, na medida em que pode estabelecer um processo de organização do trabalho pedagógico em dois diferentes níveis como "organização da escola [e]como um todo e como organização da sala de aula. Incluindo sua relação com o contexto social 
imediato, procurando observar a visão de totalidade" (VEIGA, 2002, p. 2).

Como se pode compreender, o planejamento na escola tem uma função estratégica, no sentido de estabelecer de modo democrático os fins organizacionais, as estratégias e meios para realizá-los. Mas afinal, qual então tem sido a contribuição do modelo de planejamento, proposto pela política do PDE, para pensar a instituição educacional em sua globalidade e na sua complexidade? Que implicações esse formato de planejamento traz na perspectiva da aproximação ou do distanciamento dos princípios da gestão democrática? $O$ que pensam diretores, professores e técnicos sobre a sua repercussão no ambiente escolar? Qual o nível de autonomia a escola tem dentro desta política?

Deve-se considerar que a elaboração do planejamento é a condição técnica imperativa para que a escola tenha acesso a recursos financeiros do PDDE. Nessa perspectiva, de alguma forma a escola deve realizá-lo, formalizar uma proposta operativa para a escola, condição direta para justificar o recebimento dos recursos, como afirma um dos diretores, deve a escola, para obter os recursos, "seguir orientações do PDDE Interativo" (Dir 1). Na prática isso quer dizer que o representante da escola deve confirmar a análise dos dados de suas últimas avaliações, apresentados pela plataforma online do PDDE. Esse processo é explicado por um entrevistado, como sendo um levantamento dos problemas e ao mesmo tempo um indicativo das prioridades a serem realizadas pela equipe escolar. Lembrou o técnico entrevistado, o diagnóstico " [...] é também fornecido pelo MEC, na plataforma de consolidação de dados que auxilia a escola encontrar seus problemas" (Téc 3). Confirmar a opção de leitura dos dados, na prática significa reduzir o planejamento a uma opção de ação apontada pela função de "análise" apresentada no sistema 'Interativo', acerca da situação da escola, sem considerar dados qualitativos relativos a sua cultura, contexto em que está situada, entre outros.

No discurso dos entrevistados pode-se encontrar duas distintas leituras sobre 0 significado deste tipo de consulta. A primeira nega que este tipo de elaboração do PDE, por consulta, tenha significado a existência de um processo de efetiva participação, "não houve grande participação, apenas consulta" (Prof. EM1). A segunda afirma que o formato do planejamento foi democrático, contou com os interessados "foi realizada com a participação de todos" (Prof. EM3). O procedimento a que se refere os entrevistados, uma simples confirmação de um diagnóstico, dificilmente mobilizará pessoas para um processo político de participação em níveis de engajamento da comunidade escolar e do seu conselho na elaboração do plano da escola.

Deve-se considerar que o mecanismo 'interativo' disponibilizado pelo PDDE 'exige' que a escola tome ciência de seus resultados, concorde e confirme a análise automática dos dados, o que indica uma apreciação, mesmo que na perspectiva de uma lógica puramente formal, a partir das informações disponibilizadas pelo sistema online, ao mesmo tempo em que se induz a opção por ações de intervenção com vistas a melhoria dos resultados. Porém, este formato não considera qualquer contexto em que os dados poderiam fazer sentido, ou seja, é como se os ambientes físicos, culturais, históricos das escolas fossem todos iguais. Desta forma as decisões são tomadas sem necessariamente contar com a efetiva participação, por um processo de escolha coletiva, como destaca um dos diretores, as prioridades na sua escola foram definidas "[...] internamente, sem uma participação maior" (Dir 5).

Na prática esse processo pode reduzir o planejamento a constatação, confirmação da análise dos resultados da avaliação IDEB e do Censo Escolar, apresentados pelo PDDE interativo, o que esvazia o planejamento como um espaço político de efetivo fomento à participação. Deve-se considerar que esse princípio é essencialmente um processo de interação, diálogo, uma ação cooperativa que possibilita o surgimento de novas ideias e estratégias de gestão democrática. Não pode ser confundido com autogestão, pois apenas o engajar-se numa atividade já existente não é participação. Já que a participação preenche uma função antropológica, ela compõe ritos, tempos e modalidades, é realizada em um ambiente humano em que o engajamento é estimulado e realizado em diferentes níveis. É por si um processo política de afirmação de interesses e de concepções de mundo.

Nesse sentido, a participação, diferentemente, tem a função de assegurar a igualdade política de todos na organização do trabalho pedagógico, na definição do funcionamento da escola, um princípio 
institucional para promover a democratização do espaço escolar "um processo de aprendizado e de luta que vislumbra nas especificidades da prática social e em uma relativa autonomia[...]" (DOURADO, 1998, p. 79).

Outro aspecto que revela, nesta política, a fragilidade da participação democrática é o modo como ocorre a priorização e a efetivação das ações. Atribuir prioridades a demandas de uma instituição é certamente algo que pode vir a mobilizar pessoas e grupos, a partir de seus empenhos e de suas percepções. Como destaca um dos diretores, na escola "[...] fazemos uma reunião para votarmos as prioridades. Foi realizado um levantamento das problemáticas da escola e assim priorizamos as urgências, [...] pois a verba nem sempre dá para suprir as necessidades da escola" (Dir 5). Os recursos do PDE não são suficientes para garantir o cumprimento das demandas que foram identificadas e priorizadas. Esse é um de seus limites, os recursos suprem apenas algumas "urgências", em um tempo e cronograma que difere da dinâmica e cronograma de necessidade da escola. $\mathrm{Na}$ prática, $\mathrm{O}$ não atendimento satisfatório às prioridades, se torna um elemento que pode desencadear um sentimento de frustação de quem 'decidiu' e isso tende a fragilizar a continuidade da participação, na medida em que não estimula o engajamento de pessoas, mesmo que em uma atividade já existente, como no caso o PDE, uma ação com sua própria estrutura e finalidade.

A participação é nesse sentido apontada como uma das dificuldades na execução do PDE, confirmada na fala de um dos professores, "no PDE, a dificuldade é envolver pessoas" (Prof. M1), mesmo que, teoricamente, a participação seja sua principal estratégia de gestão. 0 envolvimento dos integrantes da escola no processo de decisão em torno do funcionamento e da organização é o principal meio para assegurar a gestão democrática. Na prática é esse envolvimento que possibilita aos integrantes da escola desenvolver sobre ela conhecimentos sobre a dinâmica, os objetivos, a estrutura organizacional e as relações com a comunidade. É ainda uma oportunidade de aproximar a comunidade escolar e assim tornar o ambiente de trabalho favorável.

Apesar dos limites aqui apontados, a contribuição da metodologia do PDE tem sentido enquanto ferramenta de gestão, no contexto da administração geral, ao propor o envolvimento e responsabilização das pessoas em torno dos resultados, de modo a assegurar o cumprimento dos objetivos organizacionais. Aplicada na escola, conforme destaca um dos diretores, o PDE "foi e é de suma importância, pois ele auxilia a escola a realizar melhor o seu trabalho: focalizar sua energia, assegurar que sua equipe trabalhe para atingir os mesmos objetivos e avaliar e adequar sua direção em resposta a um ambiente em constante mudança" (Dir 6). Tem assim um forte componente técnico que pode auxiliar na gestão escolar, como destaca um dos entrevistados, "o PDE contribui para que a escola possa enfrentar seus problemas, o PDE e uma ferramenta que auxilia a gerir a escola" (Téc 3). Porém, não considera a tamanha complexidade do sentido político-pedagógico da cultura escolar.

No conjunto dessa política, o PDE interage com um poderoso sistema de recompensa, o Bônus de Desempenho Educacional $(B D E)^{6}$, em função de uma mudança que a escola é motivada a "atingir" em relação ao desempenho de seus estudantes, como afirma o diretor anteriormente citado, os professores "têm seu esforço reconhecido e recebe uma gratificação do Estado pelo bom desempenho, sem contar a satisfação de saber que seu aluno conseguiu alcançar seu objetivo" (Dir 6). Este entrevistado julga que o resultado é o fator "mais importante" na sua escola e que "nos últimos anos vem se destacando pelo seu bom desempenho", estando assim em condições adequadas à política em tela.

Não se pode desconsiderar que os objetivos postos por essa política focam o desempenho dos estudantes em apenas duas áreas do conhecimento, conforme destaca um professor, o planejamento proposto pelo PDE visa a "[...] melhoria do desempenho de Português e Matemática" (Prof. M1). A adequação da escola a esse objetivo, por si, não parece ampliar efetivamente a sua autonomia nas dimensões administrativas, políticas e pedagógicas. De outro modo, a escola persegue de forma obstinada para garantir o melhor desempenho de estudantes nessas áreas do conhecimento, em nome da competição estabelecida e a consequente premiação através

\footnotetext{
${ }^{6}$ O BDE existe desde 2008, pela lei de no 13.486 , para premiar os profissionais das escolas que cumprissem parcial ou integralmente as metas para o Idepe. A partir de 2009, o BDE passou a incluir também as GREs. O cálculo do BDE corresponde ao percentual de atingimento de metas acordadas em Termo de Compromisso assinado por cada unidade de ensino e o Secretário de Educação do Estado.
} 
do reconhecimento financeiro para os trabalhadores, assegurado por meio da política estadual de Bônus de Desempenho Educacional (BDE).

Por traz do BDE está a ideia de que o desempenho de alguém não vem de forma isolada, é associado a outro desempenho, uma forma de competição, seja da escola em relação a outra escola, ou mesmo entre estudantes de diferentes escolas. Essa lógica acaba por influenciar o processo formativo e estimular a prática da competição como um elemento 'natural' da cultura e da prática dos profissionais da educação. Conforme o discurso dos entrevistados, a competição é vista de diversas maneiras: Na forma de premiação da escola, "premiações que a escola vem recebendo; da visita do secretário de educação a escola" (Dir 1); na percepção e difusão que a escola goza de um certo status em função do nível de qualidade, expresso no discurso de um dos diretores, ao afirmar que a escola "tem mantido um bom nível no índice desde de 2014" (Dir 5).

A política da competição tem influenciado ainda a redefinição de práticas docentes, e na compreensão acerca de seu papel educativo. Como destaca um dos dirigentes, as atribuições dos docentes têm mudado, passam a atuar na direção do "[...] desempenho dos estudantes e na qualidade do ensino" (Dir 6). A ideia do dever dos docentes em atuar no desempenho dos alunos, associada a qualidade do ensino, conforme afirmada pelo diretor, aponta para o cerne desta política, a qualidade da educação centrada no desempenho limitado a duas áreas específicas do conhecimento.

A política de bonificação tem sido criticada em outros estados, como ocorreu em São Paulo, em que o secretário de educação se posicionou crítico a esse modelo de meritocracia, e quanto ao risco de que essa política contribua para perpetuar a desigualdade, ao afirmar

[...] que de início o estado
embarcour nessa
tendênciar de
meritocraciar (...) Eu
tenho um receio de que
as escolas mais frágeis,
vulneráveis, não
consigam [se beneficiar].
Porque a performance
delas é sempre mais
dificultada, a região é
vulnerável, as famílias são

menos preparadas. Eu tenho muito receio de que a política de bonificação vá perpetuando a desigualdade (NALINI, 2018, p. 1).

Ele destaca ainda a mudança de foco na função da escola, perde a oportunidade de criar espaços para um aprendizado alegre e prazeroso, em detrimento da competição de uma cultura que se estabelece para a competição, "[...] estamos ensinando a concorrer, competir, isso o consumismo já ensina. A escola tem de ser espaço que o aprendizado se faça com alegria, com prazer" (NALINI, 2018, p. 1).

A ideia de planejamento difundida e fomentada pela política do PDE, não dá conta da desafiadora necessidade de escola, de pensar sua organização e, em especial, o processo educativo na sua complexidade. É necessário resgatar, de outro modo, a função estratégica do Projeto Político Pedagógico (PPP), defendido como o principal instrumento da gestão escolar, que como processo democrático de decisões,

[...] preocupa-se em
instaurar uma forma de
organização do trabalho
pedagógico que supere os
conflitos, buscando
eliminar as relações
competitivas, corporativas
e autoritárias, rompendo
com a rotina do mando
impessoal e racionalizado
da burocracia que permeia
as relações no interior da
escola, diminuindo os
efeitos fragmentários da
divisão do trabalho que
reforça as diferenças e
hierarquiza os poderes de
decisão (VEIGA, 2002, p.
2).

Na política do PDE o PPP é mantido enquanto exigência formal para compor o processo de adesão. No entanto, essa forma de planejamento não parece ser suficientemente considerado no seu papel preponderante sobre as demais políticas, como expressão autônoma da comunidade educativa, ou seja, como um "processo permanente de reflexão e discussão 
dos problemas da escola, na busca de alternativas viáveis à efetivação de sua intencionalidade" (VEIGA, 2002, p. 3).

Como observado anteriormente, o desempenho é a marca da gestão da escola a partir do conjunto da política desenhada pelo PDE, e em Pernambuco acelerada pela política de gestão por resultados. Mas afinal, qual o nível de aceitação da escola aos princípios desta política? Em que ela está de acordo e/ou que aspectos contesta? Que impactos o PDE tem no ambiente escolar?

\section{CONCLUSÃO}

Este artigo pretendeu compreender as implicações do Plano de Desenvolvimento da Escola no planejamento da escola pública, a partir da experiência da rede estadual em Pernambuco, no período de 1998 a 2017. Verificou-se que este plano, marco de uma política que envolve o PDDE como mediador do fomento, passou por mudanças nos seus procedimentos no período de 1998 a 2017, sem no entanto alterar seus fins, mantendo-se como mecanismo de intervenção no ambiente da gestão escolar para firmar uma cultura de resultados, na perspectiva da administração gerencial.

$\mathrm{Na}$ atual conjuntura, pensar a gestão da escola requer considerar os limites com que se apresenta o cenário político e econômico, as restrições de financiamento impostos pelas políticas de ajuste fiscal, a partir de 2016, e o retrocesso que isso representa para a área educacional na afirmação do interesse público sob o privado.

Assim, o discurso da política do PDE Escola em análise, deve ser compreendido na complexidade com ele vem se formando, uma continuidade às ações do Projeto Nordeste na educação (final da década de 1980), na sequência da lógica de financiamento com que se apresentou o Programa de Manutenção e Desenvolvimento do Ensino Fundamental (PMDE) e na relação direta com o PDDE, como vem sendo mantido e fortalecido a partir de 1995. Além disso, vincula-se a lógica dos resultados medidos pelos sistemas de avaliação em larga escala, desenvolvido pelo poder central e duplicado em alguns estados, a exemplo do índice de Desenvolvimento da Educação de Pernambuco (IDEPE). Soma-se ainda a política da meritocracia e da recompensa através do $B D E$, estabelecendo gratificação por eventuais melhorias nos resultados educacionais.

É assim que ganha sentido a prática de projetos de melhoria dos resultados da avaliação externa empreendida como controle externo da escola. Como se observou, essa política vem vingando por mais de duas décadas e não aponta avanços na perspectiva da defesa de um financiamento integral necessário para a manutenção da escola pelo poder público. Observou-se ainda que o gerenciamento estabelecido não favorece o entendimento da educação como um direito social, elemento fundamental de uma política estruturante para a sociedade. Ao contrário disto, equivocadamente fortalece a ideia de que, na escola, o problema não é a falta de recursos, mas a ausência de gestão eficaz e eficiente.

Acentua-se com esta política induz uma arriscada relação entre o público e o privado, como é o caso do modelo de Unidade Executora (UEx) proposto para gerenciar os recursos destinados as escolas públicas, o avançado sistema de monitoramento de resultados ou mesmo o sistema de recompensa, que estimula a concorrência nas escolas.

Há aspectos positivos a serem considerados, exemplo ao modelo de partilha dos recursos do salário-educação, utilizando-se de critérios com maior nível de transparência. Ainda deve-se ressaltar o formado de repasse de recursos às escolas, eles dão maior visibilidade ao desafio da autonomia na definição dos gastos, e apontam para o sentido e uma nova prática a ser desenvolvida à luz desse princípio. Ainda é salutar o avanço na compilação de dados históricos obtidos por cada escola, condensado em uma única plataforma, o que permite o reconhecimento, ao longo dos anos, do significado da atuação e dos compromissos de cada organização com a sociedade e ainda questionar sua imagem frente aos dados $e$ valorizar outros aí não revelados, dado seu sentido simbólico e não mensurável.

No que se refere a gestão interna da escola, os efeitos da política encabeçada pelo PDE Escola têm levado a uma fragmentação nas relações de poder no espaço escolar, em contraposição aos mecanismos colegiados de gestão de natureza democrática. A ênfase técnico-operacional acentuada pelo PDDE interativo concentrou ainda mais as opções de política escolar nas mãos dos diretores, implicando restrições às práticas democráticas de 
gestão e contrariando um de seus princípios elementares, como órgão coletivo de gestão escolar, reduzindo-a a possibilidade de decidir burocraticamente sobre destinação e priorização de recursos cada vez mais escassos. Neste sentido a nossa proposta é de pensar a cultura e a gestão escolar a partir do paradigma da ação comunicativa. Sobretudo para romper com este modelo tecnicista e fragmentado e repensar este modelo a partir dos sujeitos em ação. Partindo das intersubjetividades e das funções linguísticas no universo das Instituições Educativas enrijecidas por linguagens autocráticas propulsoras de relações assimétricas.

Compreende-se que a questão da participação, pensada como estratégia democrática de hegemonia, tem se revelado nesta política uma função técnica para aprimorar o controle burocrático. Distancia-se desse modo de uma instância de poder partilhado, de espaço de decisão em torno de um projeto de escola, que permita aos seus agentes, realizar escolhas sobre os fins e os meios, na defesa de um projeto de sociedade.

Percebeu-se, em contraposição, que o processo de participação no PDE Escola acabou por negar a função dos colegiados, ao mesmo tempo em que não facilita perceber a escola, na sua complexidade. Outro elemento observado é que este Plano não garante a execução das decisões tomadas no planejamento, produzindo assim, uma sensação de que os educadores, por falta de recursos, devem desistir dos direitos às condições de trabalho e ensino digno a seus estudantes.

Esta política tem resultado em um forte sistema de controle e regulação das variáveis quantitativas do ambiente escolar, tais como sua estrutura, a sua condição material, os resultados da aprendizagem e demais dados originários da base de dados do Censo Escolar e dos sistemas de avaliação nacional, tais como o IDEB.

Percebeu-se a continuidade da ressignificação dos conceitos educacionais, e por parte dos professores, uma adesão passiva ou mesmo uma significativa conformação aos princípios educacionais propostos pelo gerencialíssimo da atual política, possivelmente amparados pela política da meritocracia e da recompensa desenvolvida através do BDE.

Neste contexto, a gestão democrática ainda está distante de ser alcançada no ambiente escolar, pois os princípios políticos de autonomia e de participação fundamentais neste sistema de poder, no PDE e PDDE assumem um significado técnico e operacional e não um sentido políticopedagógico.

Um desafio que se coloca na atual conjuntura é efetivação da perspectiva política estabelecida no PNE (2014/2024), que ratificou o princípio da gestão democrática da educação pública, a partir das Meta 19. Gestão democrática está associada ao financiamento público, orientada por

[...] critérios técnicos de mérito e desempenho e à consulta da comunidade escolar; sinaliza a priorização de repasses da União na área da educação aos entes que tenham aprovado a legislação específica regulamentando a gestão democrática; incentiva as conferências estimula espaços de participação tais como: grêmio, associações de pais, conselhos escolares; sinaliza para favorecimento de processos de autonomia pedagógica, administrativa e de gestão financeira nos estabelecimentos de ensino e para o desenvolvimento de programas de formação de diretores e gestores escolares, bem como, de aplicação de prova nacional específica para o provimento de cargo de diretor (DOURADO, 2017, págs. 153-154).

Aqui se estabeleceu a necessidade de regulamentação da gestão democrática, incentivo a gestão colegiada por meio dos diversos conselhos, a autonomia pedagógica, administrativa e administrativa e a formação específica para diretores e gestores das escolas. Além disso, o desafio da década e para o futuro da escola e de sua gestão, está na efetivação da política de financiamento, como estabelecida na meta 20, que sinaliza, entre outros, "para a ampliação do investimento público em educação pública, o fortalecimento dos mecanismos e dos instrumentos que asseguram a transparência e o controle social na utilização dos recursos públicos aplicados à educação; [...]" (DOURADO, 2017, p. 154).

Ao final deste texto chega-se a consciência de que o estudo ora realizado não produz uma análise suficiente para compreensão da complexidade que representa o atual contexto 
da política de gestão educacional no Brasil. Vivese na atualidade um tumultuado contexto político em que se impôs uma contrarreforma na educação, em uma velocidade sem precedentes, o que exige dos pesquisadores um cuidadoso processo de registro e análise, como forma de subsidiar novos caminhos a frente desta temática. É portanto preponderante a necessidade de aprofundamento desta temática, dada a sua relevância na promoção de uma educação de melhor qualidade, com reflexos no desenvolvimento humano, na formação cidadã.

\section{REFERÊNCIAS}

ALARCAO. Isabel. (org) Escola Reflexiva e Nova Racionalidade. Porto Alegre, Ed. Artmed. 2001. Disponível em: <http://www.ia.ufrrj.br/ppgea/conteudo/conteu do-2008.

2/2SF/Lia/Escola\%20Reflexiva\%20e\%20nova\%20r acionalidade.pdf>. Acesso em: 04.02.2019

BOTLER, Alice Miriam Happ. A Escola como Organização Comunicativa. 2004. (f.299). Tese (Doutorado) - Universidade Federal de Pernambuco - Programa de Pós-Graduação em Sociologia, Recife, 2004.

BOUFLEUER, José Pedro. Pedagogia da Ação Comunicativa. 3. ed. ljuí: Unijuí, 2001.

BRASIL. Ministério da Educação. Lei de Diretrizes e Bases da Educação Nacional. 1996. Disponível em:

<http://portal.mec.gov.br/arquivos/pdf/ldb.pdf $>$. Acesso em: 20 jun. 2015.

BRASIL. Ministério da Educação. PDDE interativo, $2015 . \quad$ Disponível em: $<$ http://pdeescola.mec.gov.br/index.php/pdeinterativo >. Acesso em: 12 jan. 2018.

DUBET, François. Injustiças: a experiência das desigualdades no trabalho. Santa Catarina: UFSC, 2014.

DOURADO, Luiz Fernandes. Plano Nacional de Educação: o epicentro das políticas de estado para a educação brasileira. Goiânia: Editora da Imprensa Universitária./ANPAE, 2017.

DOURADO, Luiz Fernandez. A escolha de dirigentes escolares: políticas e gestão da educação no Brasil. In: FERREIRA, N. S. C. (org.). Gestão Democrática da educação: atuais tendências, novos desafios. São Paulo: Cortez, 1998.

FAIRCLOUGH, N. Discurso e Mudança Social. Coord. de tradução: Izabel Magalhães. Brasília: Ed. Universidade de Brasília, 2001.

HABERMAS, Jurgen. Técnica e Ciência como Ideologia. Lisboa: Edições 70, 1997.

HERMANN, Nadja. Educação e Racionalidade: conexões e possibilidades de uma Razão Comunicativa na Escola. Porto Alegre: EDIPUCRS, 1996.

MATOS, Manuel S. Teorias e Práticas da Formação: contributos para a Reabilitação do Trabalho Pedagógico. Porto: Edições ASA, 1999.

MULLER, Pierre; SUREL, Yves. A análise das políticas públicas. Tradução de Agemir Bavaresco e Alceu Ferraro. Pelotas: Educar, 2002.

NALINI, José Renato. Secretário avalia aspectos negativos de bônus e avaliações. [mar. 2018]. Paulo Saldaña. Folha de São Paulo, São Paulo, 07 de março de 2018. Versão online. Disponível em:

$<$ https://www1.folha.uol.com.br/educacao/2018 /03/bonus-a-professor-pode-perpetuardesigualdade-diz-secretario-de-alckmin.shtml>. Acesso em: 18 mar. 2018

PERNAMBUCO. Secretaria de Educação. PGE: Plano de Gestão da Escola - SEE/PE / DDEE Produto 2. Recife: SEE, 2002.

PINTO, Glesse Custodio. Análise do programa PDDE interativo: instrumento de aperfeiçoamento da gestão escolar. 2015. 78f., Monografia (Bacharelado) - Universidade de Brasília - Bacharelado em Gestão de Políticas Públicas), Brasília, 2015.

RODRIGUES, Luiz Alberto Ribeiro. Políticas de gestão escolar: uma análise do plano de desenvolvimento da escola na região da Mata Norte de Pernambuco (1999- 2007). Recife: EDUPE, 2013.

SILVA, L. C. F. da. Estado e política de gestão financeira para a escola pública: A autonomia da 
escola no PDDE. Dissertação (Mestrado). 2005. f. 240. Universidade Federal do Pará - Centro de Educação, Belém, 2005.

TOMMASI, L. de. Financiamentos do Banco Mundial no setor educacional brasileiro: os projetos em fase de implementação. In: TOMASSI, L. de; WARD M. J; HADDAD, S. (Orgs). O Banco Mundial e as políticas educacionais. 5a ed. São Paulo: Cortez, 2007.

VEIGA, I. P. A. Projeto Político-Pedagógico da escola: uma construção coletiva. In: VEIGA, I. P. A (org) Projeto político-pedagógico da escola: uma construção possível. 14. ed. Campinas: Papirus, 2002.

Recebido para avaliação: 25/08/2018

Revisado em: 23/10/2018

Aceite Final: 11/11/2018 